\title{
Identification of elderly fallers by muscle strength measures
}

\author{
Mirjam Pijnappels • (Petra) J. C. E. van der Burg • \\ Neil D. Reeves $\cdot$ Jaap H. van Dieën
}

Accepted: 2 November 2007 / Published online: 11 December 2007

(C) The Author(s) 2007

\begin{abstract}
For efficient prevention of falls among older adults, individuals at a high risk of falling need to be identified. In this study, we searched for muscle strength measures that best identified those individuals who would fall after a gait perturbation and those who recovered their balance. Seventeen healthy older adults performed a range of muscle strength tests. We measured maximum and rate of development of ankle plantar flexion moment, knee extension moment and whole leg push-off force, as well as maximum jump height and hand grip strength. Subsequently, their capacity to regain balance after tripping over an obstacle was determined experimentally. Seven of the participants were classified as fallers based on the tripping outcome. Maximum isometric push-off force in a leg press apparatus was the best measure to identify the fallers, as cross-validation of a discriminant model with this variable resulted in the best classification (86\% sensitivity and $90 \%$ specificity). Jump height and hand grip strength were strongly correlated to leg press force $(r=0.82$ and 0.59 , respectively) and can also be used to identify fallers, although with slightly lower specificity. These results indicate that whole leg extension strength is associated with the ability to prevent a fall after a gait perturbation and might be used to identify the elderly at risk of falling.
\end{abstract}

M. Pijnappels ( $₫)$ · (Petra) J. C. E. van der Burg · J. H. van Dieën Research Institute MOVE, Faculty of Human Movement Sciences, Vrije Universiteit Amsterdam, Van der Boechorststraat 9, 1081 BT Amsterdam, The Netherlands

e-mail: m.pijnappels@fbw.vu.nl

N. D. Reeves

Institute for Biophysical and Clinical Research into Human

Movement, Manchester Metropolitan University, Cheshire, UK
Keywords Ageing $\cdot$ Fall risk $\cdot$ Classification · Physical capacity $\cdot$ Perturbation

\section{Introduction}

One-third of those over 65 years of age fall at least once per year. About $50 \%$ of them will suffer recurrent falls (Masud and Morris 2001). Even in the large group of relatively fit and healthy elderls, falls are common (Stel et al. 2003a). Consequences of falls are known to contribute substantially to the prevalence of health problems (Lord and Dayhew 2001), health care costs (Stevens et al. 2006), and to lost quality of life (Cumming et al. 2000). Prevention of falls is therefore imperative and should address the people at risk and the physiological causes of falling (Lord et al. 2003).

Numerous epidemiological studies have shown that falls are associated with many risk factors (for overviews see e.g., Lord et al. 2001). Reduced muscle strength, especially of the lower limbs, has been indicated as one of the most important risk factors for falls (Lord et al. 2003; de Rekeneire et al. 2003; Moreland et al. 2004; Rao 2005; Rubenstein 2006; Skelton et al. 2002). Experimental studies can provide causal verification and insight into the contribution of muscle strength to fall incidence in standardized situations. For example, tripping over an obstacle, which accounts for up to $60 \%$ of falls (Berg et al. 1997; Roudsari et al. 2005), can be induced and measured in older adults in experimental settings (Pavol et al. 1999; Pijnappels et al. 2005c; Schillings et al. 2005). Previous findings provided insight into the (neuro)physical requirements of preventing a fall after tripping over an obstacle (for overviews see van Dieën et al. 2005; Pijnappels et al. 2007). It was shown that older adults were less able to successfully recover balance than younger adults, due to lower maximum ankle moments and 
lower rates of moment generation around all leg joints during the push-off phase of balance recovery (Pijnappels et al. 2005c). These results suggest that leg strength may be the limiting factor in preventing a fall.

Pavol et al. (2002) have investigated the relation between muscle strength and the outcome of an induced trip. In a group of older adults, they compared isolated ankle, knee, and hip flexion and extension strength between those who recovered from a trip, and those who fell. Although some strong adults fell, presumably due to their high walking velocity, they also found that muscle strength was lower in several other fallers.

If low muscle strength indeed is a physiological cause of falls, this raises the question whether people with a high risk of falling can be identified by means of relatively simple maximum muscle strength measures. The aim of this study was to find the best predictor of falls after a gait perturbation in a standardized situation, from a range of muscle strength measures in older adults.

There are numerous maximum strength capacity measures that have been assessed in aged populations, for example to evaluate training interventions (Ferri et al. 2003; Reeves et al. 2005b; Verschueren et al. 2004) or to compare fallers with non-fallers (Gehlsen and Whaley 1990; Pavol et al. 2002). We focused on the most common measures by use of a dynamometer, isometric ankle and knee extension moment and rate of moment generation. In addition to isolated joint moments, total lower limb push-off force can be measured by a leg press dynamometer (Gehlsen and Whaley 1990). Performance on a maximum vertical jump could be a more functional test used to assess maximum lower limb strength (Izquierdo et al. 1999; Runge et al. 2004). Finally, hand grip strength is thought to reflect general body strength and has been used as predictor of falls in epidemiological studies (Pluijm et al. 2006).

Elderly volunteers performed these maximum strength capacity tests and we measured their ability to prevent a fall after being tripped. We hypothesized that maximum muscle strength measures can be used to differentiate fallers from non-fallers. If so, this would not only allow identification of potential fallers, but also indicate specific limiting factors to target with exercise-based interventions.

\section{Methods}

Seventeen healthy older adults participated [ 10 women: age 71 (SD 4.5) years, mass 75 (SD 9) kg, height 1.68 (SD $0.09) \mathrm{m}]$. All participants were fit and had no orthopedic, neuromuscular, cardiac or visual problems. The Ethics Committees the VU Medical Center and of the Manchester Metropolitan University approved the procedure and all subjects gave their written, informed consent before participation.

\section{Capacity measures}

Participants performed a series of static and dynamic maximum force generating capacity tests. First, isometric ankle plantar flexion moment and knee extension moment (maximum as well as rate of moment development) were assessed using a dynamometer. In view of constraints on equipment and subject availability, nine of the participants were tested using an isokinetic dynamometer (Cybex Norm, New York, USA) (Reeves et al. 2004) and eight using a custom-built dynamometer (de Ruiter et al. 2004) (Fig. 1a, b). Isometric knee extension moment was measured in both settings with a knee joint angle of $90^{\circ}\left(0^{\circ}\right.$ full extension) and a hip angle of $85^{\circ}\left(0^{\circ}\right.$ supine position). Isometric plantar flexion moment was measured using the Cybex with the knee in full extension and the ankle at $0^{\circ}$ (anatomical position). In the custom ankle dynamometer, the knee joint was fixed at $90^{\circ}$ and to obtain a similar gastrocnemius muscle length compared to that during the tests using the Cybex, the ankle angle was set at $20^{\circ}$ dorsiflexion (see equation in Reeves et al. 2005a, p. 2280). Plantar flexion moment of the right leg (push-off leg in the tripping experiments) and knee extension of the left leg (landing leg for tripping) were measured. Measurements resulted in comparable values between settings and were repeated 3 times with 3 min rest between contractions. Subjects first performed a maximum isometric contraction by increasing their effort in a linear ramp fashion, so that maximum moment was reached within $2 \mathrm{~s}$ and then maintained for 3 $4 \mathrm{~s}$. From these measurements, the maximum moments (ANKLE ${ }_{\mathrm{MAX}}$ and $\mathrm{KNEE}_{\mathrm{MAX}}$ ) were calculated, relative to body mass. Next, subjects were instructed to increase their moment from 0 to at least $70 \%$ of their maximum as quickly as possible, without counter movement. Moment onset ( $2 \mathrm{~N} \mathrm{~m}$ above baseline) was determined and rate of moment development (ANKLE $E_{\text {RTD }}$ and $\mathrm{KNEE}_{\mathrm{RTD}}$ ) was calculated over the first $100 \mathrm{~ms}$ after moment onset and expressed relative to body mass.

Maximum leg press push-off force of each lower limb was measured for all subjects using the same leg press fitness instrument (MR Systems, Haarlem, the Netherlands) (Fig. 1c). Subjects performed a one-legged (horizontal) push-off, starting with the ankle joint angle at $0^{\circ}$ and the knee joint angle at $30^{\circ}$. This position was comparable to the configuration of the support limb during tripping (Pijnappels et al. 2005a, c). The fore-foot was positioned on a $10 \times 10 \mathrm{~cm}$ force transducer (AMTI M3-1000, Watertown, USA) that was mounted in the push-off platform. Subjects first performed a maximum isometric contraction with the sled fixed and subsequently a maximum dynamic contraction 

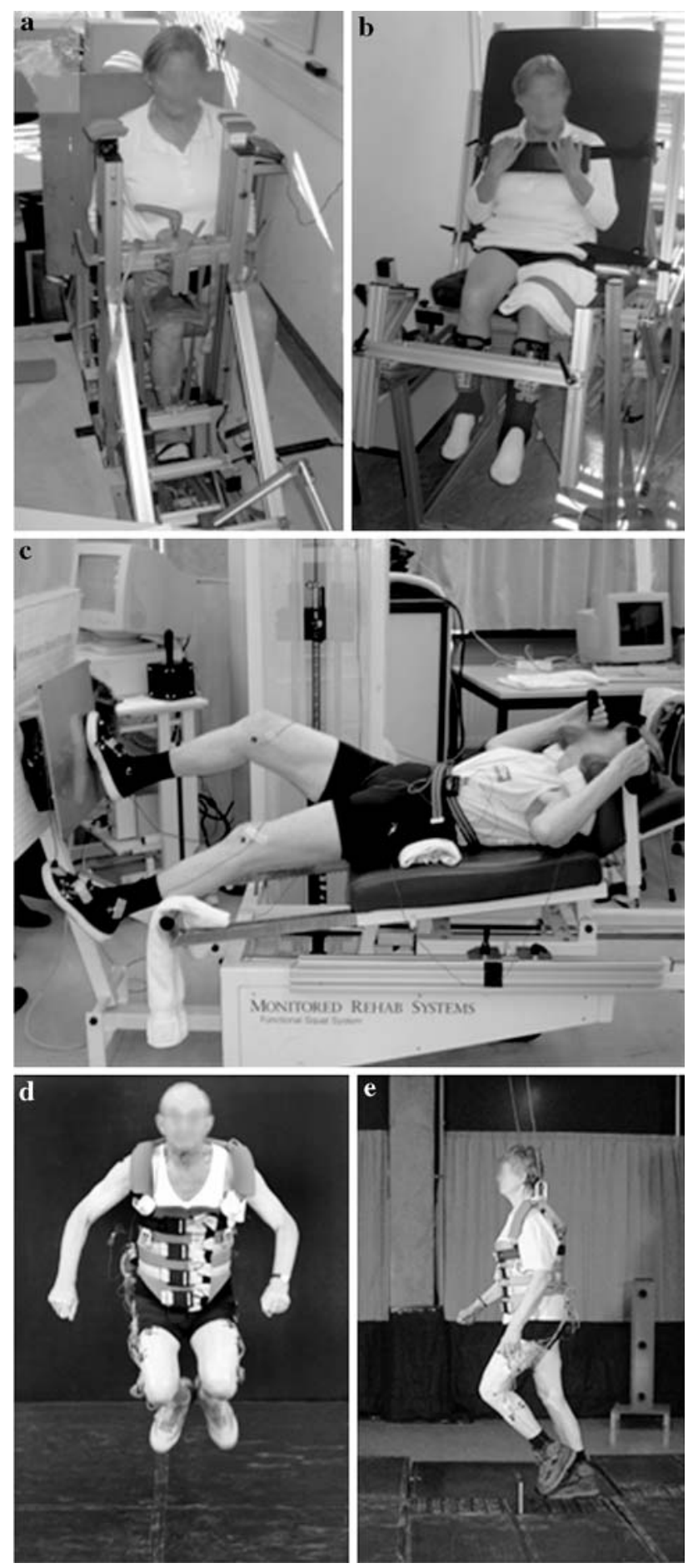

Fig. 1 Pictures of the experimental settings for a right plantar flexion moment measurements, b left knee extension moment measurements, c leg press push-off force measurements, $\mathbf{d}$ jumping measurements, and e tripping experiments

with the weight stack set equal to body mass, so the only external resistance was the mass and inertia of the body and sled. Both conditions were repeated 3 times for both legs with a $3 \mathrm{~min}$ rest between contractions. The maximum horizontal leg press push-off force (LEGPRESS ${ }_{\text {MAX }}$ ) was calculated from the isometric contractions and the rate of force development (LEGPRESS RFD $_{\text {) }}$ ) was calculated from the dynamic contractions over $100 \mathrm{~ms}$ after onset of force generation, averaged over both legs and expressed relative to body mass.

For the jumping measurement, subjects performed a maximum two-legged counter movement jump (Fig. 1d). Position data of markers placed bilaterally on the trochanter major were measured by Optotrak cameras (Northern Digital, Waterloo, Canada). From the best of two attempts, maximum jump height ( $\mathrm{JUMP}_{\mathrm{H}}$ ) was calculated as the vertical distance between the highest averaged hip position during jumping and averaged hip height during normal standing.

Hand grip strength was measured using a digital straingauge dynamometer (Takei TKK 5401, Takei Scientific Instruments, Tokyo, Japan). Subjects performed two maximum force trials with each hand. The maximum values of the right and left hand (in $\mathrm{kg}$ ) were added together $\left(\mathrm{HAND}_{\mathrm{F}}\right)$.

\section{Tripping measurements and falls}

The ability to prevent a fall after a gait perturbation was determined by tripping measurements (Pijnappels et al. 2005c). Subjects walked at a self-selected velocity over a $12 \mathrm{~m}$ walkway. Fourteen $15 \mathrm{~cm}$ high obstacles were hidden at the left side and seven obstacles were hidden at the right side of the walkway, over a total distance of $1.5 \mathrm{~m}$ (Fig. 1e). In 2-5 of 40 trials, one of the obstacles suddenly appeared (based on online kinematic data) to catch the subject's left swing leg at mid-swing, usually causing an elevating strategy for balance recovery. This strategy involves the limb contacting the obstacle being elevated over the obstacle (Eng et al. 1994; Schillings et al. 2000), whilst the contralateral support limb provides push-off. Subjects were aware that they could be tripped on either leg, but did not know whether and where an obstacle would appear in the ongoing trial. They wore a safety harness that moved along a track above the walkway. Subjects were classified as fallers based on visual detection of full body support by the harness (checked by video), in more than $50 \%$ of the tripping trials.

\section{Statistical analysis}

Pearson's coefficients of correlation between the capacity measures were calculated. In case of high correlations between the dependent variables, as we found, the power of a multivariate analysis of variance (MANOVA) decreases when the expected effect sizes are reasonably large and consistent in the same direction (Cole et al. 1994). We therefore focused on separate univariate ANOVAs to determine which capacity measures differed between fallers and 
non-fallers. The variables that appeared to be determinants of falls from the ANOVAs were used in discriminant analyses, in order to find the variable(s) best discriminating between fallers and non-fallers and to determine sensitivity and specificity. In addition, a cross-validation was performed to assess the generalizability of the predictive models; each case was classified by the functions derived from all other cases (leave-one-out-classification). SPSS statistical software was used and the level of significance was set at $p<0.05$.

\section{Results}

Tripping measurements and falls

Seven of the participants (all women) were fully supported by the safety harness in more than half of the tripping trials. Six of them fell in all trials; the other fell in three out of five trials. Non-fallers were never fully supported by the safety harness. The averaged walking velocity was 1.38 (SD $0.17) \mathrm{m} / \mathrm{s}$ and did not differ between fallers and non-fallers $(p=0.488)$.

Capacity measurement as predictor for falls

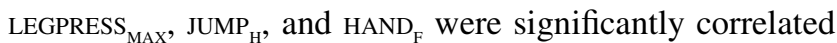
with almost all other capacity measures (Table 1). Leg press push-off force was not significantly different between the left and right leg of the subjects $(p=0.496$ for LEGPRESS $_{\text {MAX }}$ and $p=0.149$ for LEGPRESS $\left.{ }_{\mathrm{RFD}}\right)$, there was no signifi-

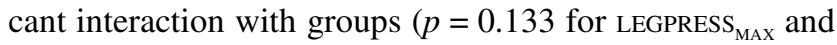
$p=0.919$ for LEGPRESS $_{\mathrm{RFD}}$ ), and the values were highly correlated between legs (overall, $r=0.813, p<0.001$ for LEGPRESS $_{\mathrm{MAX}}$ and $r=0.829, p<0.001$ for LEGPRESS $_{\mathrm{RFD}}$ ).

All but one of the univariate ANOVAs resulted in significant differences, indicating several measures to be different between fallers and non-fallers (Fig. 2). Ankle and knee capacity measures (both maximum and rate of moment development), maximum leg press force, jump height, and grip strength were significantly lower for fallers compared to non-fallers.
These seven variables were entered in a stepwise discriminant analysis, which resulted in a significant model $(p=0.001)$ with LEGPRESS $_{\text {MAX }}$ as the only predictor. This model resulted in $94 \%$ correctly classified cases and a cross-validation of $88 \%$ (Table 2). For comparison, discriminant analyses with the ankle and knee capacity tests (stepwise) and with jump height and grip strength as single predictors also resulted in significant predictive models, with slightly lower predictive values (Table 2). Figure 3 presents the distribution of individual $\mathrm{JUMP}_{\mathrm{H}}$, and $\mathrm{HAND}_{\mathrm{F}}$ values, both in relation to LEGPRESS ${ }_{\mathrm{MAX}}$.

\section{Discussion}

It is important to identify individuals most at risk of falling, because they should be considered with priority for receiving targeted exercise interventions aimed at reducing the incidence of falls. This study investigated the possibility to identify fallers from maximum strength measures that could be applied in clinical settings. The results showed that participants who fell after a gait perturbation could indeed be identified based on these measures. Especially, a classification model based on maximum leg press push-off force yielded high sensitivity and specificity in cross-validation.

The subjects in this study were relatively fit and healthy older adults. Nevertheless, muscle strength varied greatly between subjects, with coefficients of variation between subjects ranging from 23 to $60 \%$ for all strength measures. Pavol et al. (2002) found that not only people with low muscle strength, but also the stronger people had a higher risk of falling after a trip. This was explained by a higher walking velocity in the stronger group, which increases the demands for adequate balance recovery. These subjects mainly used a lowering strategy, which implies that they were tripped at late swing (Eng et al. 1994; Pijnappels et al. 2005b). Since the trip was induced manually, it may be that faster walkers were more likely to be tripped in late swing. It is therefore unclear whether velocity or instant of trip initiation was responsible for a number of stronger subjects falling. In our study, however, walking velocity was not
Table 1 Correlation coefficients between capacity measures are in bold.

${ }^{\text {a }} p<0.05$

b $p<0.01$

\begin{tabular}{llllllll}
\hline & ANKLE $_{\text {RTD }}$ & KNEE $_{\text {MAX }}$ & KNEE $_{\text {RTD }}$ & LEGPRESS $_{\text {MAX }}$ & LEGPRESS $_{\text {RFD }}$ & JUMP $_{\mathrm{H}}$ & HAND $_{\mathrm{F}}$ \\
\hline ANKLE $_{\text {MAX }}$ & $\mathbf{0 . 6 3}^{\mathbf{b}}$ & 0.23 & 0.32 & $\mathbf{0 . 7 6}^{\mathbf{b}}$ & 0.37 & $\mathbf{0 . 6 1}^{\mathbf{b}}$ & 0.40 \\
ANKLE $_{\text {RTD }}$ & 1 & 0.36 & $\mathbf{0 . 7 0}^{\mathbf{b}}$ & $\mathbf{0 . 6 8}^{\mathbf{a}}$ & 0.40 & $\mathbf{0 . 6 5}^{\mathbf{b}}$ & $\mathbf{0 . 5 1}^{\mathbf{a}}$ \\
KNEE $_{\text {MAX }}$ & & 1 & $\mathbf{0 . 7 2}^{\mathbf{b}}$ & $\mathbf{0 . 5 3}^{\mathbf{a}}$ & -0.02 & 0.34 & $\mathbf{0 . 7 1}^{\mathbf{b}}$ \\
KNEE $_{\text {RTD }}$ & & & 1 & $\mathbf{0 . 5 7}^{\mathbf{a}}$ & 0.36 & $\mathbf{0 . 5 5}^{\mathbf{a}}$ & $\mathbf{0 . 7 8}^{\mathbf{b}}$ \\
LEGPRESS $_{\text {MAX }}$ & & & & 1 & 0.33 & $\mathbf{0 . 8 2}^{\mathbf{b}}$ & $\mathbf{0 . 5 9}^{\mathbf{a}}$ \\
LEGPRESS $_{\text {RFD }}$ & & & & & 1 & 0.29 & 0.23 \\
JUMP $_{\mathrm{H}}$ & & & & & & 1 & $\mathbf{0 . 6 9}^{\mathbf{b}}$ \\
\hline
\end{tabular}



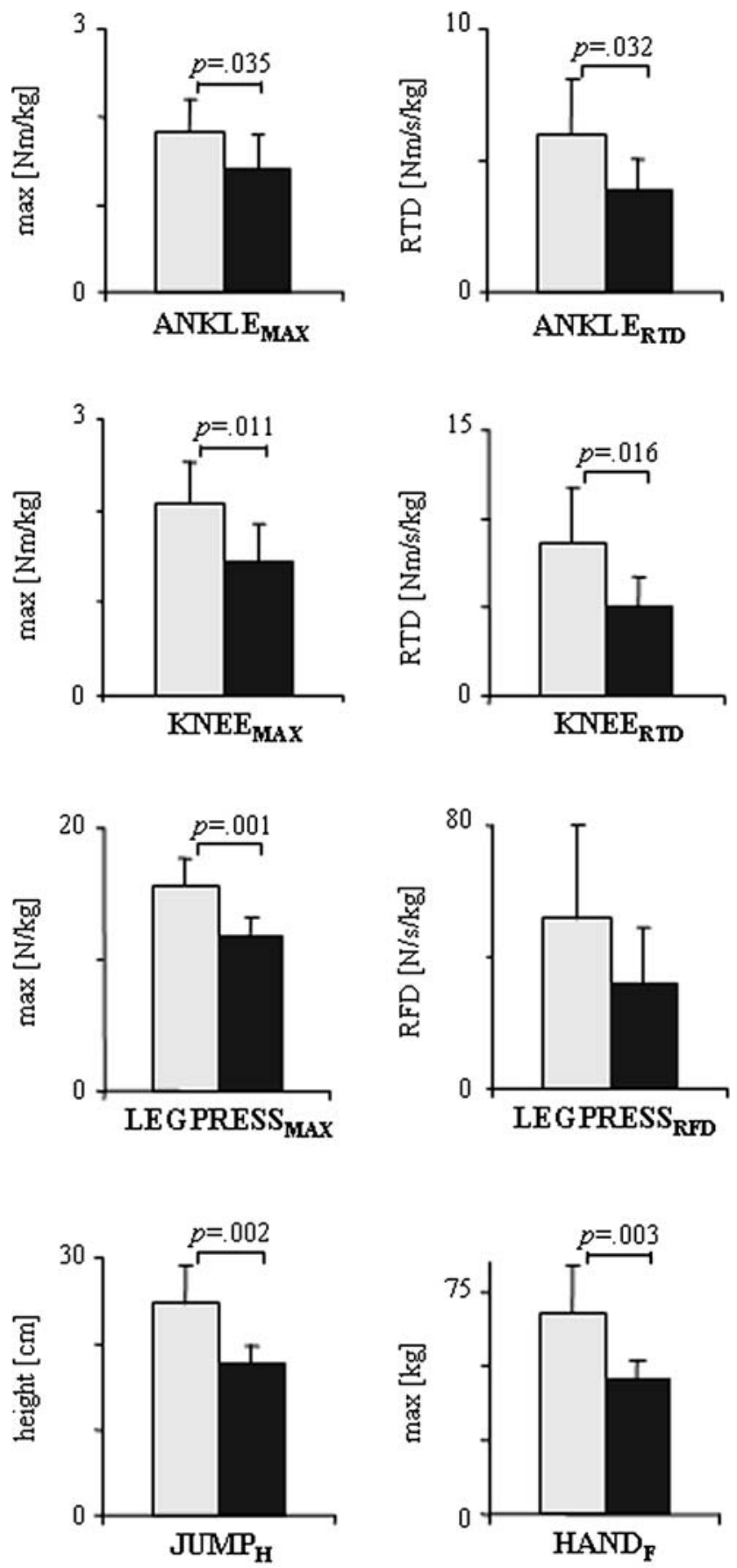

$\square$ non-fallers $\square$ fallers

Fig. 2 Averaged group differences in capacity measures between fallers and non-fallers. Maximum $(\max )$ and rate of moment development (RTD) of plantar flexion moment ( $\mathrm{ANKLE}_{\mathrm{MAX}}$ and $\mathrm{ANKLE}_{\mathrm{RTD}}$ ) and knee extension moment $\left(\mathrm{KNEE}_{\mathrm{MAX}}\right.$ and $\left.\mathrm{KNEE}_{\mathrm{RTD}}\right)$, maximum and rate of force development (RFD) of leg press push-off force (LEGPRESS ${ }_{\text {MAX }}$ and LEGPRESS $\left._{\text {RFD }}\right)$, jump height (JUMP $\left.{ }_{H}\right)$, and hand grip strength $\left(\mathrm{HAND}_{\mathrm{F}}\right)$. Significant differences between groups are indicated with $p$-values

different between fallers and non-fallers and in the range of "fast walkers" of the study of Pavol, even though we did not standardize it and explicitly instructed subjects to walk at their normal and comfortable velocity. Furthermore, we were able to trip all subjects at exactly mid-swing (when the toe height is minimal and a trip is most likely in daily life). This implies that the effect of the trip by impact with the obstacle was equal over subjects and could not affect the outcome of the trip. Yet, this also may suggest that instant of trip initiation and in a more heterogeneous group, differences in preferred walking velocity must be taken into account when attempting to identify fallers.

Although we were able to trip our subjects repeatedly, three of the fallers and one non-faller did not complete the whole protocol up to five tripping trials, due to discomfort. Nevertheless, the fallers fell in all trials and the non-faller did not fall in four tripping trials. Hence, the number of tripping trials did not affect the classification of the participants.

Hip extension and knee flexion strength were not measured, but might also contribute to fall prediction, as the rate of development of hip extension and knee flexion moments during push-off after tripping were found to be lower in older fallers compared to young adults (Pijnappels et al. 2005c). Since especially hip extension capacity is quite difficult to determine (especially in a clinical setting) and given limitations in the total number of capacity measurements to be performed in a single session, these variables were not included in the present study.

During the push-off phase of a tripping reaction, the knee is generating an internal flexion moment while extention (Pijnappels et al. 2005a). Preliminary data suggest that a high extension moment is required in the leg making ground contact at landing (van Dieën et al. 2005) and a limited capacity to generate sufficiently high knee extension moments might thus increase the fall risk. In this study, fallers could not position their recovery foot adequately and were therefore fully supported by the safety harness, mostly even before landing. This underlines that most of the balance recovery takes place during push-off by the support limb. However, as falls can also occur after landing (Pavol et al. 2001), the requirements for landing need further investigation.

Fallers and non-fallers were classified in this study based on their ability to prevent a fall after an experimentally induced gait perturbation. In daily life, there are many various ways in which people fall. Furthermore, this experimental study included a small number of participants, which might have influenced the predictive values. A prospective study with a larger cohort is necessary to generalize the results of this study to the prediction of falls in daily life.

Overall, sufficient leg extension strength is required for adequate balance recovery after tripping. This might explain why a capacity measure that involves extension of all lower limb joints (i.e., leg press push-off) yielded the 
Table 2 Predictive variables resulting from stepwise discriminant analyses and cross-validation on capacity measures

\begin{tabular}{|c|c|c|c|c|}
\hline Capacity measures & $\begin{array}{l}\text { Predictive } \\
\text { variable }\end{array}$ & $p$ & $\begin{array}{l}\text { Discriminant analysis } \\
\text { (sensitivity/specificity\%) }\end{array}$ & $\begin{array}{l}\text { Cross-validation } \\
\text { (sensitivity/specificity\%) }\end{array}$ \\
\hline $\begin{array}{l}\text { LEGPRESS }_{\text {MAX }}, \text { ANKLE }_{\text {MAX }}, \text { ANKLE }_{\text {MAX }}, \\
\text { KNEE }_{\text {MAX }}, \text { KNEE }_{\text {RTD }}, \text { JUMP }_{H}, \text { HAND }_{F}\end{array}$ & LEGPRESS $_{\text {MAX }}$ & 0.001 & $86 / 100$ & $86 / 90^{\mathrm{a}}$ \\
\hline $\mathrm{ANKLE}_{\mathrm{MAX}}, \mathrm{ANKLE}_{\mathrm{RTD}}, \mathrm{KNEE}_{\mathrm{MAX}}, \mathrm{KNEE}_{\mathrm{RTD}}$ & $\mathrm{ANKLE}_{\mathrm{MAX}}, \mathrm{KNEE}_{\mathrm{MAX}}$ & 0.007 & $71 / 90$ & $71 / 90$ \\
\hline $\mathrm{JUMP}_{\mathrm{H}}$ & $\mathrm{JUMP}_{\mathrm{H}}$ & 0.002 & $86 / 90$ & $86 / 80$ \\
\hline $\mathrm{HAND}_{\mathrm{F}}$ & HAND $_{\mathrm{F}}$ & 0.003 & $86 / 80$ & $86 / 80$ \\
\hline
\end{tabular}

${ }^{\mathrm{a}}$ Best predictive model
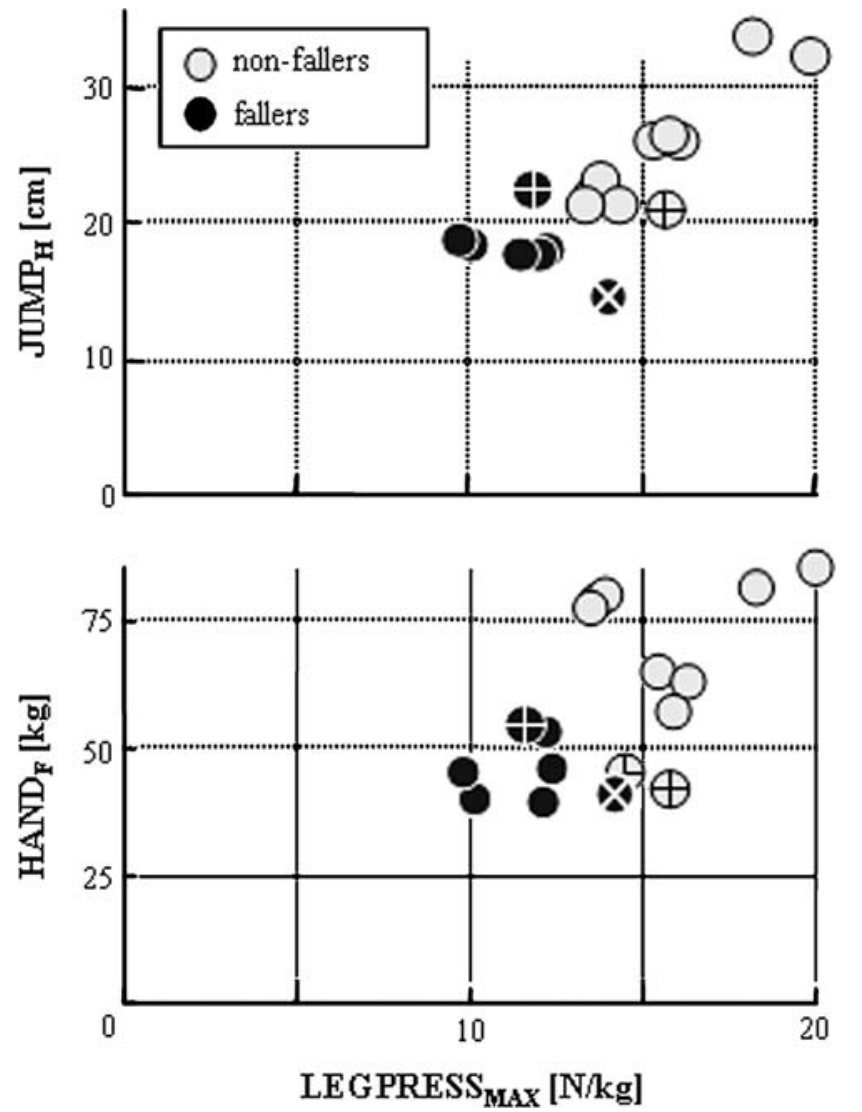

Fig. 3 Distribution of the individual values of maximum leg press push-off force (LEGPRESS ${ }_{\text {MAX }}$ ) with jump height $\left(\mathrm{JUMP}_{\mathrm{H}}\right.$ ) and hand grip strength $\left(\mathrm{HAND}_{\mathrm{F}}\right)$ for fallers and non-fallers. Crosses indicate the incor-

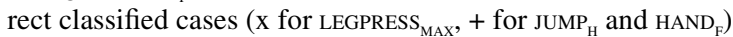

best identification of fallers. This one-legged task is highly similar to the actual movement during the push-off phase of tripping (Pijnappels et al. 2005a, c).

Jumping also requires rapid moment generation and was therefore expected to be a good and practical measure of whole lower limb strength. Studies have shown that maximum jumping forces are lower in the elderly (Izquierdo et al. 1999; Runge et al. 2004) and related to balance performance (Izquierdo et al. 1999). Jump height indeed resulted in good sensitivity and specificity. This task was less similar to the actual tripping action than the leg press and does not solely reflect strength, as it also requires complex coordination of many joints. One might argue that the older fallers, who were all women, may have been more afraid to jump maximally than their counterparts. However, jump height was strongly correlated to maximum leg press push-off force, which was measured in a secure and comfortable setting. Jumping performance, therefore, more likely reflects lower limb strength than an effect of gender or fear.

Fall incidents and the ensuing injury process are multifactorial. Muscle strength is only one of many factors that associate with falls and that has to be taken into account when identifying one's fall risk. Yet, this particular factor has been indicated as one of the main causal factors for falls and is essential in risk profiles. For example, in the physiological profile approach by Lord et al. (2003) muscle force is tested in lower extremity muscle groups. However, these tests are not based on empirically demonstrated causal relations. Our experimental study allowed investigating the relation between strength measures and gait perturbations in a standardized situation. It can be questioned whether the findings in this study on tripping over an obstacle in midswing can be transferred to other fall mechanisms that occur in daily life. Yet, leg extension force has also been indicated to play an important role in other fall mechanics, such as slipping (Chambers and Cham 2007; Tang and Woollacott 1999). The results of this study may therefore contribute to improvement of risk profiles for identification of high-risk fallers, particularly by using relatively simple but specific measures of maximum strength.

For clinical use, a maximum vertical jump test might be more practical than the leg press test, as it requires little instrumentation. Rittweger et al. (2004) demonstrated that such a test is feasible also for subjects over the age of 80 and that reliability is high.

Hand grip strength is a common clinically used strength capacity measure. It has been shown in epidemiological studies to be related to leg extension strength and to be associated to recurrent falling in daily life (Stel et al. 2003b). Our data indeed showed that grip strength is significantly correlated with lower limb capacities and that it can be used to identify fallers from non-fallers. Although 
hand grip strength is easy to measure and assumed to be related to whole body strength, one should bear in mind that this measure may be less accurate as a predictor for falls it is not task specific for balance recovery.

With respect to fall prevention, the associations found in this study suggest that maximum whole leg extension force is an important target in conducting exercise-based interventions. In a pilot study, we showed that lower limb resistance training has the potential to improve balance recovery, as older trainers improved more in moment generation upon tripping than controls (Pijnappels et al. 2007). It can be questioned whether fall prevention training should focus on strength training alone, as task-specific training of motor skills has been shown to be important (Bieryla et al. 2007; Owings et al. 2001; Troy and Grabiner 2005). A combination of both strength and balance training is most likely to be most beneficial for reduction of fall incidence (Gillespie et al. 2003). Finally, it should be noted that training effects are only valuable if task-specific requirements can be achieved and it can be questioned whether this is the case in older and more frail elderly. Therefore, resistance training may be particularly useful in the group of relatively fit and healthy elderly (Barry and Carson 2004; Hunter et al. 2004; Latham et al. 2004; Macaluso and De Vito 2004), which might prevent these people from becoming recurrent fallers.

\section{Conclusion}

Relatively simple and accessible measures of maximum strength did identify elderly fallers from non-fallers after a standardized gait perturbation. The capacity to generate maximum extension force by the whole leg (e.g., in a leg press apparatus or during jumping) resulted in the best classification of older fallers and non-fallers. Follow up studies on larger cohorts with a wide range of muscle strength and walking velocities are necessary to generalize these results towards a valid prediction of fall risk.

Acknowledgments This project has been financially supported by the Netherlands Organisation for Scientific Research (NWO), the Foundation "De Drie Lichten" and "Stichting Annafonds", the Netherlands.

Open Access This article is distributed under the terms of the Creative Commons Attribution Noncommercial License which permits any noncommercial use, distribution, and reproduction in any medium, provided the original author(s) and source are credited.

\section{References}

Barry BK, Carson RG (2004) Transfer of resistance training to enhance rapid coordinated force production by older adults. Exp Brain Res 159(2):225-238
Berg WP, Alessio HM, Mills EM, Tong C (1997) Circumstances and consequences of falls in independent community-dwelling older adults. Age Ageing 26(4):261-268

Bieryla KA, Madigan ML, Nussbaum MA (2007) Practicing recovery from a simulated trip improves recovery kinematics after an actual trip. Gait Posture 26(2):208-213

Chambers AJ, Cham R (2007) Slip-related muscle activation patterns in the stance leg during walking. Gait Posture 25(4):565

Cole D, Maxwell S, Arvey R, Salas E (1994) How the power of MANOVA can both increase and decrease as a function of the intercorrelations among the dependent variables. Psychol Bull 115(3):465-474

Cumming RG, Salkeld G, Thomas M, Szonyi G (2000) Prospective study of the impact of fear of falling on activities of daily living, SF-36 scores, and nursing home admission. J Gerontol A Biol Sci Med Sci 55(5):M299-M305

de Rekeneire N, Visser M, Peila R, Nevitt MC, Cauley JA, Tylavsky FA, Simonsick EM, Harris TB (2003) Is a fall just a fall: correlates of falling in healthy older persons. The health, aging and body composition study. J Am Geriatr Soc 51(6):841-846

de Ruiter CJ, Kooistra RD, Paalman MI, de Haan A (2004) Initial phase of maximal voluntary and electrically stimulated knee extension torque development at different knee angles. J Appl Physiol 97(5):1693-1701

Eng JJ, Winter DA, Patla AE (1994) Strategies for recovery from a trip in early and late swing during human walking. Exp Brain Res 102(2):339-349

Ferri A, Scaglioni G, Pousson M, Capodaglio P, Van Hoecke J, Narici MV (2003) Strength and power changes of the human plantar flexors and knee extensors in response to resistance training in old age. Acta Physiol Scand 177(1):69-78

Gehlsen GM, Whaley MH (1990) Falls in the elderly: part II, balance, strength, and flexibility. Arch Phys Med Rehabil 71(10):739-741

Gillespie LD, Gillespie WJ, Robertson MC, Lamb SE, Cumming RG, Rowe BH (2003) Interventions for preventing falls in elderly people (Cochrane Review). In: The Cochrane Library, Issue 3. Wiley, Chichester

Hunter GR, McCarthy JP, Bamman MM (2004) Effects of resistance training on older adults. Sports Med 34(5):329-348

Izquierdo M, Aguado X, Gonzalez R, Lopez JL, Hakkinen K (1999) Maximal and explosive force production capacity and balance performance in men of different ages. Eur J Appl Physiol Occup Physiol 79(3):260-267

Latham NK, Bennett DA, Stretton CM, Anderson CS (2004) Systematic review of progressive resistance strength training in older adults. J Gerontol A Biol Sci Med Sci 59(1):48-61

Lord SR, Dayhew J (2001) Visual risk factors for falls in older people. J Am Geriatr Soc 49(5):508-515

Lord SR, Sherrington C, Menz HB (2001) Falls in older people: risk factors and strategies for prevention. Cambridge University Press, Cambridge

Lord SR, Menz HB, Tiedemann A (2003) A physiological profile approach to falls risk assessment and prevention. Phys Ther 83(3):237-252

Macaluso A, De Vito G (2004) Muscle strength, power and adaptations to resistance training in older people. Eur J Appl Physiol 91(4):450-472

Masud T, Morris RO (2001) Epidemiology of falls. Age Ageing 30(Suppl 4):3-7

Moreland JD, Richardson JA, Goldsmith CH, Clase CM (2004) Muscle weakness and falls in older adults: a systematic review and meta-analysis. J Am Ger Soc 52(7):1121-1129

Owings TM, Pavol MJ, Grabiner MD (2001) Mechanisms of failed recovery following postural perturbations on a motorized treadmill mimic those associated with an actual forward trip. Clin Biomech 16(9):813-819 
Pavol MJ, Owings TM, Foley KT, Grabiner MD (1999) The sex and age of older adults influence the outcome of induced trips. J Gerontol A Biol Sci Med Sci 54(2):M103-M108

Pavol MJ, Owings TM, Foley KT, Grabiner MD (2001) Mechanisms leading to a fall from an induced trip in healthy older adults. J Gerontol A Biol Sci Med Sci 56(7):M428-M437

Pavol MJ, Owings TM, Foley KT, Grabiner MD (2002) Influence of lower extremity strength of healthy older adults on the outcome of an induced trip. J Am Geriatr Soc 50(2):256-262

Pijnappels M, Bobbert MF, van Dieën JH (2005a) How early reactions in the support limb contribute to balance recovery after tripping. J Biomech 38(3):627-634

Pijnappels M, Bobbert MF, van Dieën JH (2005b) Control of support limb muscles in recovery after tripping in young and older subjects. Exp Brain Res 160(3):326-333

Pijnappels M, Bobbert MF, van Dieën JH (2005c) Push-off reactions in recovery after tripping discriminate young subjects, older non-fallers, and older fallers. Gait Posture 21(4):388-394

Pijnappels M, Reeves ND, Maganaris C, van Dieën J (2007) Tripping without falling; lower limb strength, a limitation for balance recovery and a target for training in the elderly. J Electromyogr Kinesiol. doi:10.1016/j.jelekin.2007.06.004

Pluijm SMF, Smit JH, Tromp EAM, Stel VS, Deeg DJH, Bouter LM, Lips P (2006) A risk profile to identify community-dwelling elderly at high risk for recurrent falling: results of a three-year prospective study. Osteop Int 17(3):417-425

Rao SS (2005) Prevention of falls in older patients. Am Fam Physician 72(1):81-88

Reeves ND, Narici MV, Maganaris CN (2004) Effect of resistance training on skeletal muscle-specific force in elderly humans. J Appl Physiol 96(3):885-892

Reeves ND, Maganaris CN, Ferretti G, Narici MV (2005a) Influence of 90 day simulated microgravity on human tendon mechanical properties and the effect of resistive countermeasures. J Appl Physiol 98(6):2278-2286

Reeves ND, Maganaris CN, Narici MV (2005b) Plasticity of dynamic muscle performance with strength training in elderly humans. Muscle Nerve 31(3):355-364

Rittweger J, Schiessl H, Felsenberg D, Runge M (2004) Reproducibility of the jumping mechanography as a test of mechanical power output in physically competent adult and elderly subjects. J Am Geriatr Soc 52(1):128-131
Roudsari BS, Ebel BE, Corso PS, Molinari NAM, Koepsell TD (2005) The acute medical care costs of fall-related injuries among the U.S. older adults. Injury 36(11):1316

Rubenstein LZ (2006) Falls in older people: epidemiology, risk factors and strategies for prevention. Age Ageing 35(Suppl 2):ii37-ii41

Runge M, Rittweger J, Russo CR, Schiessl H, Felsenberg D (2004) Is muscle power output a key factor in the age-related decline in physical performance? A comparison of muscle cross section, chair-rising test and jumping power. Clin Physiol Funct Imaging 24(6):335-340

Schillings AM, Van Wezel BMH, Mulder T, Duysens J (2000) Muscular responses and movement strategies during stumbling over obstacles. J Neurophysiol 83(4):2093-2102

Schillings I, Mulder T, Duysens J (2005) Stumbling over obstacles in older adults compared to young adults. J Neurophysiol 94(2):1158-1168

Skelton DA, Kennedy J, Rutherford OM (2002) Explosive power and asymmetry in leg muscle function in frequent fallers and non-fallers aged over 65. Age Ageing 31(2):119-125

Stel VS, Pluijm SMF, Deeg DJH, Smit JH, Bouter LM, Lips P (2003a) A classification tree for predicting recurrent falling in community-dwelling older persons. J Am Geriatr Soc 51(10):1356-1364

Stel VS, Smit JH, Pluijm SMF, Lips P (2003b) Balance and mobility performance as treatable risk factors for recurrent falling in older persons. J Clin Epidemiol 56(7):659-668

Stevens JA, Corso PS, Finkelstein EA, Miller TR (2006) The costs of fatal and non-fatal falls among older adults. Inj Prev 12(5):290 295

Tang PF, Woollacott MH (1999) Phase-dependent modulation of proximal and distal postural responses to slips in young and older adults. J Gerontol A Biol Sci Med Sci 54(2):M89-M102

Troy KL, Grabiner MD (2005) The presence of an obstacle influences the stepping response during induced trips and surrogate tasks. Exp Brain Res 161(3):343-350

van Dieën JH, Pijnappels M, Bobbert MF (2005) Age-related intrinsic limitations in preventing a trip and regaining balance after a trip. Safety Sci 43(7):437-453

Verschueren SMP, Roelants M, Delecluse C, Swinnen S, Vanderschueren D, Boonen S (2004) Effect of 6-month whole body vibration training on hip density, muscle strength, and postural control in postmenopausal women: a randomized controlled pilot study. J Bone Min Res 19(3):352-359 